Www.jmscr.igmpublication.org

Impact Factor 3.79

ISSN (e)-2347-176x ISSN (p) 2455-0450

crossref DOI:_http://dx.doi.org/10.18535/jmscr/v3i10.54

Journal Of Medical Science And Clinical Research

IGM Publication

An official Publication of IGM Publication

\title{
Study the Correlation between Anthropometric Parameters and Biochemical Cardiovascular Risk Markers in Elderly Hypertensive Egyptian Patients
}

\author{
Authors \\ Marwa A. Saad M.D ${ }^{*}$, Marwa H. Mahmood, M.D ${ }^{2}$ \\ ${ }^{1}$ Lecturer of Internal Medicine, Geriatric Department, Faculty of Medicine, Alexandria University; \\ ${ }^{2}$ Lecturer of Clinical and Chemical Pathology, Clinical Pathology Department, Faculty of Medicine, \\ Alexandria University \\ Corresponding Author \\ Marwa A. Saad M.D \\ Lecturer of Internal Medicine, Geriatric Department, Faculty of Medicine, Alexandria University
}

\begin{abstract}
Hypertension is a serious public health problem among elderly Egyptians. The prevalence of overweight/ obesity is also increasing in alarming proportions among the elderly, and it is correlated with the prevalence of hypertension, one of the major risk factors for cardiovascular diseases, and also strongly correlated with atherogenic dyslipidemia parameters. We aimed to determine the correlation between lipid profile, and high sensitivity $C$-reactive protein ( $h s$-CRP) with anthropometric indices, as indicators of additional cardiovascular risk in a population of elderly hypertensive Egyptian patients.119 elderly hypertensive patients of both genders were enrolled in this study divided into three groups according to age. Height, weight, BMI, WC, WHR, blood pressure, lipid profile, and hs-CRP were measured for all participants. No statistical difference between the different age groups in both genders as regard height, weight, BMI, and WHR. WC tends to decrease significantly with age in both genders. A statistically significant difference was noted between different age groups only in women as regards; total cholesterol ( $p<0.013)$, and HDL-chlevels $(p<0.015)$. While, a statistical significant difference between was noted in both women and men regarding; $L D L-c h(p<0.016$, and $p<0.021$ respectively), and triglyceride (TG) levels ( $p<0.011$, and $p<0.032$ respectively).Both SBP, and DBP tend to increase with age, with no statistical significant difference was noted between the different age groups in both genders. ( $p<0.136$ and $p<0.0 .365$ in women, $p<0.251$, and $p<0.152$ in men).hs-CRP values tend to increase progressively with age with, a statistical significant difference between the three studied groups in both genders. ( $p<0.036$, and $p<0.013$ respectively). In group I, BMI, WC, and WHR all were correlated with lipid profile and blood pressure, while, in group II, BMI and WC, but not WHR were correlated with lipid profile and blood pressure, and in group III, none of these indices were correlated with lipid profile or blood pressure. In all studied age groups; total cholesterol, $L D L$-ch, and triglycerides were positively correlated, and HDL-ch was negatively correlated with systolic and diastolic blood pressure. Total cholesterol, LDL-ch, and triglycerides were positively correlated, and HDL-ch was negatively correlated with hs-CRP. Both systolic and diastolic blood pressures were positively correlated with hs-CRP. We concluded that anthropometric indices are strongly correlated with hypertension, one of the major risk factors for cardiovascular diseases, and also strongly
\end{abstract}


correlated with atherogenic dyslipidemia parameters. Assessing the hs-CRP levels may thus provide additive value in predicting cardiovascular risks.

Keywords: Hypertension, Elderly Egyptians, Anthropometric indices, Lipid panel, Cardiovascular risk, hs-CRP

\section{Introduction}

Hypertension is one of the major public health problem worldwide. ${ }^{(1)}$ Sustained hypertension over time is a major risk factor for, coronary artery disease, stroke, aortic aneurysm, peripheral artery disease, and chronic kidney disease. ${ }^{(2)}$ Hypertension is defined as a systolic blood pressure (SBP) $\geq 140 \mathrm{~mm} \mathrm{Hg}$, or a diastolic blood pressure $(\mathrm{DBP}) \geq 90 \mathrm{~mm} \mathrm{Hg}$, or taking antihypertensive medication. ${ }^{(3)}$ Hypertension is a worldwide epidemic. Overall, approximately $20 \%$ of the world's adults are estimated to have hypertension. Worldwide, approximately 1 billion people have hypertension, contributing to more than 7.1 million deaths per year. ${ }^{(4)}$ The prevalence dramatically increases in patients older than 60 years.A progressive rise in BP with increasing age is observed. Age-related hypertension appears to be predominantly systolic rather than diastolic. The SBP rises into the eighth or ninth decade, whereas the DBP remains constant or declines after age 40 years. $^{(5)}$ The prevalence of hypertension was highest in the age group 60-74 years $(51 \%){ }^{(6)}$

Hypertension may be primary or secondary. Primary or essential hypertension which is defined as high blood pressure with no obvious underlying cause accounts for $90-95 \%$ of adult cases. ${ }^{(7)}$ It may develop as a result of environmental or genetic causes. ${ }^{(8)}$ Secondary hypertension results from an identifiable cause. Kidney diseases are the most common secondary cause of hypertension as polycystic kidney disease, chronic kidney disease, urinary tract obstruction, reninproducing tumor, and renovascular hypertension. ${ }^{(9)}$ Hypertension can also be caused by endocrine conditions, such as Cushing's syndrome, hyperthyroidism, hypothyroidism, acromegaly, Conn's syndrome or hyperaldosteronism, hyperparathyroidism and pheochromocytoma. ${ }^{(9)}$ Other causes of secondary hypertension include obesity, sleep apnea, pregnancy, coarctation of the aorta, excessive liquorice consumption and certain prescription medicines, herbal remedies and illegal drugs. ${ }^{(10)}$

Hypertension is a major risk factor for cardiovascular and renal disease, and numerous clinical trials including studies in older subjects have documented that effective treatment improves survival and confers cardiovascular benefits. ${ }^{(11)}$ Untreated hypertension carries high risk of mortality and is often described as a silent killer. Untreated mild to moderate hypertension, may be associated with a risk of atherosclerotic disease in $30 \%$ of people and organ damage in $50 \%$ of people within 8-10 years after onset. For every $20 \mathrm{~mm} \mathrm{Hg}$ systolic or $10 \mathrm{~mm} \mathrm{Hg}$ diastolic increase in $\mathrm{BP}$ above $115 / 75 \mathrm{~mm} \mathrm{Hg}$, the mortality rate for both ischemic heart disease and stroke doubles. ${ }^{(12)}$ In the Framingham Heart Study, the age-adjusted risk of congestive heart failure was higher in patients in the highest BP was compared to the lowest BP. ${ }^{(13)}$ Multiple Risk Factor Intervention Trial (MRFIT) data showed that the relative risk for coronary artery disease mortality was higher for persons with mild to severe hypertension than it was for persons with normal BP. ${ }^{(14)}$

Framingham risk scores are widely used for prediction of future cardiovascular disease events. However, they don't include anthropometric measures, which now considered a major cardiovascular disease risk factor. Studies have shown that the risk assessment of cardiovascular health, usually performed by determining the Framingham scores, can be improved by measuring plasma markers of inflammation and anthropometric evaluation. ${ }^{(15)}$ These markers include acute phase proteins like C-Reactive Protein (CRP). ${ }^{(16)}$ Anthropometric variables have been reported in the literature as important predictors of cardiovascular risk. ${ }^{(17)}$ Many studies 
discovered that fat distribution, rather than absolute total fat, is more closely associated with these risk factors. ${ }^{(18)}$ Other studies, however, found that total body fat or body mass index (BMI), rather than its distribution, is the stronger predictor of metabolic risks. ${ }^{(19)}$ Waist-to-hip ratio (WHR) is so far the most widely used index of central fat distribution due to its benefits in routine monitoring and assessment in patients. ${ }^{(20)}$ Recent studies have shown that waist circumference (WC) is the best simple anthropometric index of abdominal visceral adipose tissue, ${ }^{(21)}$ and may also be the best index for predicting cardiovascular risks. ${ }^{(22)}$

C-reactive protein (CRP) is a liver-derived molecule that is increased in inflammatory states. Since cardiovascular disease is at least in part an inflammatory process, CRP has been investigated in the context of arteriosclerosis and subsequent vascular disorders. Based on multiple epidemiological and intervention studies, CRP elevation [high-sensitivity CRP (hsCRP)] has been shown to be associated with future major cardiovascular risk. ${ }^{(23)}$ In many studies, the relative impact of hs-CRP is at least as large as that individually of low-density lipoprotein cholesterol, high-density lipoprotein cholesterol, blood pressure, or smoking, and knowledge of hsCRP correctly reclassifies a substantial proportion of "intermediate-risk" individuals into clinically relevant higher- or lower-risk categories. ${ }^{(24)}$

Considering that, we aimed to determine the correlation between the biochemical markers including; lipid profile, and high sensitivity Creactive protein (hs-CRP) with anthropometric measurements; WC, WHR, and BMI as indicators of additional cardiovascular risk in a population of elderly hypertensive Egyptian patients.

\section{Materials and methods:}

The current study was conducted on 119 elderly hypertensive males and females aged 60 years and older who attended the geriatric outpatient clinic in the Main University Hospital, Alexandria University in the period from November 2014 till
September 2015. Participants were divided into three groups according to their age; Group (I): patients aged from 60-69 years, Group (II): age from 70-79 years, and Group (III): age more than 80 years. The proposal of this study was approved by the Ethical Committee of Faculty of Medicine, Alexandria University. The purpose and benefit of the study were explained to the participants and informed written consent was obtained from all subjects. A thorough medical history and full clinical examination were carried out for all participants.

Before measuring the blood pressure, participants were initially made to rest for 15 minutes, and asked about drinking tea or coffee, physical activity, smoking and full bladder. Then, a blood pressure was measured twice in a seated position using a standard calibrated mercury sphygmomanometer as well as a stethoscope. On the basis of the circumference of the participant's arm, a regular adult or large cuff was chosen. The cuff was placed on the participant's right arm, which is at the heart level. There was at least one minute interval between these two separate measurements, and thereafter the mean of the two measurements was considered as the participant's blood pressure, whereas the hypertensive subject who had a mean systolic blood pressure more than $140 \mathrm{~mm} / \mathrm{Hg}$ and Mean diastolic blood pressure more than 90 mmHg. ${ }^{(12)}$ Then, weight was measured, while subjects minimally clothed without shoes using digital scales and recorded to the nearest $100 \mathrm{~g}$. Height was measured using anthropometric rod, with the subject made to stand erect on a flat surface (without footwear) with feet together. ${ }^{(25)}$ Body mass index (BMI) was calculated as weight in kilograms divided by height in meters squared. The cutoff values used were: Underweight < 18.5, Normal: 18.5-24.9, Overweight: 25.0-29.9, Obese: > 30, and morbidly obese: $\geq 40$. $^{(26)}$

Waist circumference was measured using a measuring tape over the unclothed abdomen, with measurements made halfway between the lower border of the ribs and the highest point of iliac 
crest (at the umbilicus level) in the standing position. The cutoff values for waist circumference was $\geq 94 \mathrm{~cm}$ in males and $\geq 80 \mathrm{~cm}$ in females. ${ }^{(25)}$ Hip circumference was measured over light clothing at the widest point over the buttocks when viewed from the side. Waist- hip ratio (WHR) was obtained by dividing the waist circumference by hip circumference. Female Participants with WHR more than 0.8, and males with WHR more than 1.0 were considered at increased health risk. ${ }^{(25)}$

Blood samples were drawn from participants in the morning after at least 12 hours overnight fast. Blood tests were done in central laboratory of Faculty of Medicine- Alexandria University using enzymatic colorimetric tests. Blood samples sent for determination of fasting blood sugar levels, total cholesterol level, high-density lipoprotein cholesterol (HDL-ch), low-density lipoprotein cholesterol (LDL-ch), triglyceride levels, and high sensitivity C- reactive protein levels (hs-CRP).

According to National Cholesterol Education Program Expert Panel, ${ }^{(27)}$ atherogenic dyslipidemia is defined as total cholesterol level $\geq 240 \mathrm{mg} / \mathrm{dl}$, or high density lipoprotein cholesterol (HDL-Ch) less than $40 \mathrm{mg} / \mathrm{dl}$ in males, and less than 50 $\mathrm{mg} / \mathrm{dL}$ in females, or low density lipoprotein cholesterol $(\mathrm{LDL}-\mathrm{Ch}) \geq 160 \mathrm{mg} / \mathrm{dl}$ or serum triglyceride $\geq 200 \mathrm{mg} / \mathrm{dl}$. Patients with fasting blood glucose $\geq 126 \mathrm{mg} / \mathrm{dl}$ or history of diabetes were excluded from the study.

Hs-CRP serum concentrations were distributed in tertiles; first tertile: $<1 \mathrm{mg} / \mathrm{L}$ (low risk); second tertile: $1-3 \mathrm{mg} / \mathrm{L}$ (intermediate risk); and third tertile: $3-10 \mathrm{mg} / \mathrm{L}$ (high risk). Values more than $10 \mathrm{mg} / \mathrm{L}$ were considered as unspecified elevation. $^{(28)}$

The Data was collected and entered into the personal computer. Statistical analysis was done using Statistical Package for Social Sciences (SPSS/version 20) software. Arthematic mean, standard deviation, for categorized parameters, chai square test was used while for numerical data t-test was used to compare two groups while for more than two groups ANOVA test was used. To find the association between two variables, Spearman correlation coefficient test was used .The level of significant was 0.05 .

\section{Results}

The present study was conducted on 119 hypertensive elderly patients; 40 males (33.6\%), and 79 females $(66.4 \%)$. Group I: comprised 47 patients $(39.5 \%) ; 18$ males $(38.3 \%)$, and 29 females (61.7\%),their mean age was $69 \pm 2.94$ years; Group II: comprised 50 patients (42\%); 18 males $(36 \%)$, and 32 females $(64 \%)$, their mean age was $79 \pm 2.67$ years, , and Group III: comprised 22 patients (18.5\%); 7 males (31.8\%) and 15 females $(68.2 \%)$, their mean age was $94 \pm 3.61$ years.

Table 1, represents anthropometric indices in different age groups in the two genders. There was no statistical difference between the different age groups in both women and men as regard height, weight, body mass index (BMI), and waist-hip ratio (WHR). Waist circumference (WC) tends to decrease significantly with age in both genders. 
Table 1: Anthropometric indices of the studied age groups in both genders:

\begin{tabular}{|c|c|c|c|c|c|c|}
\hline & \multicolumn{3}{|c|}{ Women } & \multicolumn{3}{|c|}{ Men } \\
\hline & $\mathrm{N}$ & Range & Mean \pm S.D. & $\mathrm{N}$ & Range & Mean \pm S.D. \\
\hline \multicolumn{7}{|l|}{ Height $(\mathrm{cm})$} \\
\hline Gp. I & 29 & $159.00-170.00$ & $163.41 \pm 2.97$ & 18 & $166.00-180.00$ & $171.56 \pm 3.43$ \\
\hline Gp. II & 32 & $160.00-168.00$ & $163.06 \pm 2.02$ & 18 & $169.00-177.00$ & $172.28 \pm 2.32$ \\
\hline Gp. III & 15 & $159.00-166.00$ & $162.13 \pm 2.33$ & 7 & $169.00-174.00$ & $170.86 \pm 1.86$ \\
\hline $\mathrm{P}$ & \multicolumn{3}{|c|}{0.365} & \multicolumn{3}{|c|}{0.415} \\
\hline \multicolumn{7}{|l|}{ Weight $(\mathrm{Kg})$} \\
\hline Gp. I & 29 & $70.00-94.00$ & $82.86 \pm 6.05$ & 18 & $76.00-89.00$ & $81.44 \pm 3.90$ \\
\hline Gp. II & 32 & $72.00-86.00$ & $79.09 \pm 3.68$ & 18 & $74.00-88.00$ & $80.83 \pm 3.97$ \\
\hline Gp. III & 15 & $70.00-84.00$ & $76.60 \pm 4.03$ & 7 & $76.00-85.00$ & $81.00 \pm 3.16$ \\
\hline $\mathrm{P}$ & \multicolumn{3}{|c|}{0.132} & \multicolumn{3}{|c|}{0.335} \\
\hline \multicolumn{7}{|l|}{ BMI } \\
\hline Gp. I & 29 & $25.90-36.20$ & $31.05 \pm 2.50$ & 18 & $25.50-29.70$ & $27.71 \pm 1.39$ \\
\hline Gp. II & 32 & $26.40-33.10$ & $29.64 \pm 1.40$ & 18 & $24.50-29.70$ & $27.21 \pm 1.54$ \\
\hline Gp. III & 15 & $26.70-32.00$ & $29.05 \pm 1.68$ & 7 & $26.60-29.40$ & $27.74 \pm 0.93$ \\
\hline $\mathrm{P}$ & \multicolumn{3}{|c|}{0.254} & \multicolumn{3}{|c|}{0.425} \\
\hline \multicolumn{7}{|l|}{$\mathrm{WC}(\mathrm{cm})$} \\
\hline Gp. I & 29 & $86.00-120.00$ & $99.24 \pm 9.10$ & 18 & $84.00-100.00$ & $91.50 \pm 4.73$ \\
\hline Gp. II & 32 & $84.00-115.00$ & $94.75 \pm 8.00$ & 18 & $85.00-95.00$ & $90.71 \pm 3.90$ \\
\hline Gp. III & 15 & $80.00-95.00$ & $85.20 \pm 4.63$ & 7 & $75.00-99.00$ & $87.50 \pm 6.65$ \\
\hline $\mathrm{P}$ & \multicolumn{3}{|c|}{$0.021 *$} & \multicolumn{3}{|c|}{$0.032 *$} \\
\hline \multicolumn{7}{|l|}{ WHR } \\
\hline Gp. I & 29 & $0.86-1.20$ & $1.00 \pm 0.09$ & 18 & $0.90-1.10$ & $1.01 \pm 0.05$ \\
\hline Gp. II & 32 & $0.80-1.13$ & $0.94 \pm 0.09$ & 18 & $0.96-1.04$ & $1.00 \pm 0.03$ \\
\hline Gp. III & 15 & $0.80-0.95$ & $0.89 \pm 0.05$ & 7 & $0.88-1.04$ & $0.99 \pm 0.04$ \\
\hline $\mathrm{P}$ & \multicolumn{3}{|c|}{0.113} & \multicolumn{3}{|c|}{0.136} \\
\hline
\end{tabular}

Table 2 represents the lipid profile, systolic and diastolic blood pressures, and hs-CRP levels of the different age groups in both genders; a statistically significant difference between the studied groups was noted only in women as regards; total cholesterol ( $\mathrm{p}<0.013$ ), and high density lipoprotein cholesterol (HDL-ch)levels $(\mathrm{p}<$ 0.015). While, a statistical significant difference between the studied groups was noted in both women and men regarding; low density lipoprotein cholesterol (LDL-ch) $(\mathrm{p}<0.016$, andp $<0.021$ respectively), and triglyceride (TG) levels ( $p<0.011$, and $<0.032$ respectively).
Both Systolic blood pressure (SBP), and diastolic blood pressure (DBP) tend to increase with age, with no statistical significant difference was noted between the different age groups in both genders. $(\mathrm{p}<0.136$ and $\mathrm{p}<0.0 .365$ in women, $\mathrm{p}<0.251$, and $\mathrm{p}<0.152$ in men).

It was noticed that high sensitivity $\mathrm{C}$ - reactive protein (hs-CRP) values tend to increase progressively with age with, a statistical significant difference between the three studied groups in both women and men was noted. $(\mathrm{p}<0.036$, and $\mathrm{p}<0.013$ respectively).

Table 2: lipid profile, blood pressure, and hs-CRP in different age groups in both genders:

\begin{tabular}{|l|l|l|l|l|l|l|}
\hline & \multicolumn{2}{|l|}{ Women } & Men & \\
\hline & $\mathrm{N}$ & Range & Mean \pm S.D. & $\mathrm{N}$ & Range & Mean \pm S.D. \\
\hline Ch.(mg/dl) & & & & & & \\
\hline Gp. I & 29 & $163.00-354.00$ & $242.21 \pm 47.35$ & 18 & $154.00-260.00$ & $200.11 \pm 29.61$ \\
\hline Gp. II & 32 & $198.00-320.00$ & $243.84 \pm 32.69$ & 18 & $190.00-240.00$ & $208.39 \pm 17.52$ \\
\hline Gp. III & 15 & $195.00-260.00$ & $219.20 \pm 19.28$ & 7 & $180.00-210.00$ & $199.14 \pm 11.02$ \\
\hline P & $0.013^{*}$ & & 0.211 & \\
\hline HDL & \multicolumn{7}{|l|}{} & \multicolumn{5}{l|}{} \\
\hline Gp. I & 29 & $14.00-130.00$ & $56.48 \pm 23.90$ & 18 & $26.00-126.00$ & $57.00 \pm 24.24$ \\
\hline Gp. II & 32 & $8.00-93.00$ & $45.47 \pm 20.86$ & 18 & $28.00-77.00$ & $53.89 \pm 13.27$ \\
\hline
\end{tabular}




\begin{tabular}{|c|c|c|c|c|c|c|}
\hline Gp. III & 15 & $10.00-89.00$ & $45.60 \pm 26.26$ & 7 & $14.00-74.00$ & $54.71 \pm 20.83$ \\
\hline $\mathrm{P}$ & \multicolumn{3}{|c|}{$0.015 *$} & \multicolumn{3}{|c|}{0.125} \\
\hline \multicolumn{7}{|l|}{ LDL } \\
\hline Gp. I & 29 & $95.00-201.00$ & $151.10 \pm 33.48$ & 18 & $79.00-165.00$ & $115.06 \pm 22.35$ \\
\hline Gp. II & 32 & $130.00-201.00$ & $167.00 \pm 24.28$ & 18 & $100.00-172.00$ & $131.44 \pm 22.63$ \\
\hline Gp. III & 15 & $89.00-201.00$ & $140.87 \pm 35.40$ & 7 & $95.00-165.00$ & $117.43 \pm 24.19$ \\
\hline $\mathrm{P}$ & \multicolumn{3}{|c|}{$0.016^{*}$} & \multicolumn{3}{|c|}{$0.021 *$} \\
\hline \multicolumn{7}{|l|}{ TG } \\
\hline Gp. I & 29 & $94.00-250.00$ & $172.45 \pm 45.33$ & 18 & $90.00-199.00$ & $139.83 \pm 34.11$ \\
\hline Gp. II & 32 & $85.00-230.00$ & $156.47 \pm 40.19$ & 18 & $78.00-195.00$ & $113.94 \pm 29.72$ \\
\hline Gp. III & 15 & $99.00-210.00$ & $163.60 \pm 29.89$ & 7 & $88.00-165.00$ & $134.29 \pm 32.05$ \\
\hline $\mathrm{P}$ & \multicolumn{3}{|c|}{$0.011^{*}$} & \multicolumn{3}{|c|}{$0.032 *$} \\
\hline \multicolumn{7}{|l|}{$\mathrm{SBP}(\mathrm{mmHg})$} \\
\hline Gp. I & 29 & $135.00-165.00$ & $153.79 \pm 8.83$ & 18 & $130.00-160.00$ & $145.28 \pm 7.37$ \\
\hline Gp. II & 32 & $145.00-170.00$ & $156.41 \pm 6.75$ & 18 & $140.00-165.00$ & $149.17 \pm 7.91$ \\
\hline Gp. III & 15 & $145.00-165.00$ & $154.33 \pm 6.51$ & 7 & $145.00-160.00$ & $151.43 \pm 5.56$ \\
\hline $\mathrm{P}$ & \multicolumn{3}{|c|}{0.136} & \multicolumn{3}{|c|}{0.251} \\
\hline \multicolumn{7}{|l|}{$\mathrm{DBP}(\mathrm{mmHg})$} \\
\hline Gp. I & 29 & $80.00-105.00$ & $93.79 \pm 6.77$ & 18 & $80.00-95.00$ & $88.61 \pm 5.64$ \\
\hline Gp. II & 32 & $85.00-110.00$ & $93.91 \pm 6.06$ & 18 & $80.00-100.00$ & $91.39 \pm 5.64$ \\
\hline Gp. III & 15 & $90.00-100.00$ & $94.67 \pm 3.99$ & 7 & $90.00-95.00$ & $92.14 \pm 2.67$ \\
\hline $\mathrm{P}$ & \multicolumn{3}{|c|}{0.365} & \multicolumn{3}{|c|}{0.152} \\
\hline \multicolumn{7}{|l|}{ Hs-CRP } \\
\hline Gp. I & 29 & $0.87-9.80$ & $3.47 \pm 2.36$ & 18 & $1.10-9.40$ & $3.58 \pm 2.62$ \\
\hline Gp. II & 32 & $0.91-9.50$ & $4.32 \pm 2.68$ & 18 & $1.10-8.20$ & $3.47 \pm 2.37$ \\
\hline Gp. III & 15 & $0.87-9.40$ & $5.44 \pm 2.91$ & 7 & $5.10-9.80$ & $7.83 \pm 1.94$ \\
\hline $\mathrm{P}$ & \multicolumn{3}{|c|}{$0.036^{*}$} & \multicolumn{3}{|c|}{$0.013^{*}$} \\
\hline
\end{tabular}

In group I; a high significant positive correlation was noted between BMI, and total cholesterol level( $r=0.714$, and $\mathrm{p}<0.0001)$, LDL-ch $(r=0.720$, and $\mathrm{p}<0.0001)$, triglycerides $\quad(\mathrm{r}=0.376$, and $\mathrm{p}<0.009$ ), systolic and diastolic blood pressures $(\mathrm{r}=0.705, \quad \mathrm{p}<0.0001$, and $\mathrm{r}=0.539, \mathrm{p}<0.0001$ respectively). WC also showed a high positive correlation with total cholesterol level $(r=0.666$, and $\mathrm{p}<0.0001)$, LDL-ch $(\mathrm{r}=0.571, \mathrm{p}<0.0001)$, HDL-ch $(\mathrm{r}=0.346, \quad \mathrm{p}<0.017)$, triglycerides $(\mathrm{r}=0.310, \mathrm{p}<0.034)$, systolic and diastolic blood pressures $(\mathrm{r}=0.689, \mathrm{p}<0.0001$, and $\mathrm{r}=0.463, \mathrm{p}<$ 0.001 respectively). WHR was positively correlated with total cholesterol level ( $\mathrm{r}=0.482$, $\mathrm{p}<$ 0.001), LDL-ch ( $\mathrm{r}=0.382, \mathrm{p}<0.008)$, HDL-ch $(\mathrm{r}=0.297, \mathrm{p}<0.043)$, systolic and diastolic blood pressures $(\mathrm{r}=0.529, \mathrm{p}<0.0001$, and $\mathrm{r}=0.366, \mathrm{p}<$ 0.011 respectively), and also with hs-CRP $(\mathrm{r}=0.368, \mathrm{p}<0.014)$.

In group II, BMI was positively correlated with total cholesterol ( $\mathrm{r}=0.375, \mathrm{p}<0.0001)$, LDL-ch $(\mathrm{r}=0.789, \mathrm{p}<0.0001)$, triglycerides $(\mathrm{r}=0.791, \mathrm{p}<$ $0.0001)$, systolic and diastolic blood pressures $(\mathrm{r}=0.636, \mathrm{p}<0.0001$, and $\mathrm{r}=0.393, \mathrm{p}<0.005$ respectively), and negative correlation with HDLch $(r=-0.287, p<0.043)$. WC showed positive correlation with total cholesterol $(\mathrm{r}=0.609, \mathrm{p}<$ 0.0001), LDL-ch ( $\mathrm{r}=0.576, \quad \mathrm{p}<\quad 0.0001)$, triglycerides $(\mathrm{r}=0.617, \mathrm{p}<0.0001)$, systolic and diastolic blood pressures $(\mathrm{r}=0.368, \mathrm{p}<0.014$, and $\mathrm{r}=0.281, \mathrm{p}<0.048$ respectively), and hs-CRP $(\mathrm{r}=0.433, \mathrm{p}<0.011)$. WHR showed no significant correlation with any of studied parameters except for hs-CRP ( $r=0.319$, $\mathrm{p}<0.027)$.

In group III, BMI, WC, WHR did not show correlation with lipid profile nor blood pressure, but a negative correlation was noted between BMI and WHR with hs-CRP $(\mathrm{r}=0.426, \mathrm{p}<0.048$, and $\mathrm{r}=0.651, \mathrm{p}<0.001$ respectively).

In all studied age groups; total cholesterol, LDLch, and triglycerides were positively correlated, and HDL-ch was negatively correlated with systolic and diastolic blood pressure. Total cholesterol, LDL-ch, and triglycerides were positively correlated, and HDL-ch was negatively correlated with hs-CRP. Both systolic and diastolic blood pressures were positively correlated with hs-CRP. 
Table 3: Regression analysis of different risk factors:

Model Summary

\begin{tabular}{|l|c|c|c|c|c|c|}
\hline Model & $\mathrm{R}$ & $\mathrm{R}$ Square & $\begin{array}{c}\text { Adjusted R } \\
\text { Square }\end{array}$ & $\begin{array}{c}\text { Std. Error of the } \\
\text { Estimate }\end{array}$ & $\mathrm{F}$ & Sig. \\
\hline dimension0 1 & $.592^{\mathrm{a}}$ & .350 & .283 & .62226 & 5.240 & $.0001^{*}$ \\
\hline
\end{tabular}

Predictors: (Constant), Hs-CRP, TG, HDL, WHR, DBP, Ht , Wt , SBP, LDL, WC, BMI

Coefficientsa

\begin{tabular}{|c|c|c|c|c|c|c|}
\hline \multirow[t]{2}{*}{ Model } & & \multicolumn{2}{|c|}{ Unstandardized Coefficients } & \multirow{2}{*}{$\begin{array}{l}\text { Standardized } \\
\text { Coefficients } \\
\text { Beta }\end{array}$} & \multirow[b]{2}{*}{$\mathrm{t}$} & \multirow[b]{2}{*}{ Sig. } \\
\hline & & B & Std. Error & & & \\
\hline & (Constant) & -.591 & 7.600 & & -.078 & .938 \\
\hline & $\mathrm{Ht}$ & .011 & .045 & .075 & .250 & .803 \\
\hline & $\mathrm{Wt}$ & -.029 & .048 & -.191 & -.603 & .548 \\
\hline & BMI & .059 & .126 & .179 & .471 & 639 \\
\hline & WC & -.033 & .012 & -.379 & -2.640 & $.010 *$ \\
\hline & WHR & -1.411 & .940 & -.158 & -2.502 & $.036^{*}$ \\
\hline & HDL & -.001 & .003 & -.017 & -.174 & .862 \\
\hline & LDL & -.001 & .003 & -.040 & -.314 & .754 \\
\hline & $\mathrm{CH}$ & -.002 & .005 & -.052 & -2.658 & $.013 *$ \\
\hline & TG & -.003 & .002 & -.156 & -1.516 & .132 \\
\hline & SBP & .031 & .011 & .352 & 2.887 & $.005^{*}$ \\
\hline & DBP & .012 & .013 & .102 & .996 & .321 \\
\hline & Hs-CRP & .042 & .023 & .155 & 1.865 & $.025^{*}$ \\
\hline
\end{tabular}

a. Dependent Variable: Group

Regarding the multivariate analysis it was found that there was a significant effect of WC, WHR in combined with cholesterol level SBP and HS-CRP.

\section{Discussion}

Hypertension is a common health problem in Egypt. It has a high prevalence, whereas its rates of awareness, treatment and control are low. ${ }^{(29)}$ More than $50 \%$ of individuals older than 60 years suffered from hypertension. It is predicted that with an Egyptian population of more than 80 million, there will be approximately 15 million with hypertension and about 7 million will be in need of lifelong drug treatment and regular follow-up. ${ }^{(29)}$ Only $38 \%$ of hypertensive Egyptians are aware of having high blood pressure, only $24 \%$ receiving treatment, ${ }^{(30)}$ and up to $60 \%$ have other cardiovascular risk factors namely hypercholesterolemia, increased LDL-ch, low HDL-ch, hypertriglyceridemia, diabetes mellitus, impaired glucose tolerance and obesity. ${ }^{(31)}$ Ibrahim MM, et al stated that hypertension prevalence increased progressively with age from $7.8 \%$ in (25-34 years old) to $56.6 \%$ in those 75 years or older. ${ }^{(32)}$ The increase in blood pressure which occurs progressively throughout life has been confirmed by the European Working Party on High Blood Pressure in the Elderly (EWPHE) ${ }^{(33)}$ which showed that about two-thirds of the elderly can be defined as hypertensive. In our study, blood pressure tend to increase with age although this increase did not reach a statistical significant levels. Also in our study, 66.4\% females were hypertensive versus $33.6 \%$ males, in Ibrahim MM, et al study ;(32) hypertension was slightly more common in women than in men( $26.9 \%$ versus $25.7 \%$, respectively).

The relationship between anthropometric indices and cardiovascular risk factors have been studied extensively in adults, and their positive relationship with hypertension was recognized. ${ }^{(34,35)}$ However, few studies reported 
this relationship among the elderly. ${ }^{(36)} \mathrm{A}$ very high rate of obesity was reported among Egyptians. ${ }^{(37)}$ Obesity contributes to hypertension, high serum cholesterol, and low HDL-ch , and is independently associated with higher cardiovascular disease risk. ${ }^{(38)}$ In our study, the mean of BMI was 29.13. Mohsen J et al. ${ }^{(39)}$ found thatabdominal obesity was more common among women than men $(54.5 \%$ vs. $12.9 \%)$ and greater with older age.Based on the newly recommended criteria of obesity for the Asian-Pacific populations, ${ }^{(40)}$ over half of this population can be considered as overweight, and about one-third can be considered as obese (males $30.8 \%$ and females $38.4 \%)$.

In our study, anthropometric indices including; body mass index (BMI), waist circumference (WC), and waist-hip ratio (WHR) were strongly associated with hypertension and lipid profile, and this association increased positively with increasing age. In accordance with our results, Mueller WH, et al ${ }^{(41)}$ observed that central obesity was more closely associated with cardiovascular risks than general obesity in women. Many studies have documented that central obesity, as reflected by waist-hip ratio (WHR), is closely associated with cardiovascular diseases for both sexes. ${ }^{(42,43)}$ we also observed a strong association between these variables in both sexes. The relation between obesity indices and metabolic variables seemed to differ between men and women. On contrary, MykkanenL,et $\mathrm{al}^{(44)}$ and SpiegelmanD, et $\mathrm{al}^{(45)}$ found obesity per se, rather than its distribution, is a more significant predictor of metabolic risks.

According to Yusuf et al, ${ }^{(46)}$ study suggested that abdominal obesity, such as waist circumference and waist- hip ratio, was better risk indicator for CVD compared to BMI. Waist circumference cutoffs are more sensitive than BMI cut-offs in predicting the risk of CVD. ${ }^{(47) .}$ BMI provides an estimate of weight correction for height while the WHR estimates abdominal fat mass ${ }^{(48)}$ However, we could not provide evidence to suggest that the measurement of waist circumference and waist hip ratio among hypertensive elderly patients were more informative than BMI. In group I patients aged from 60-69 years, BMI, WC, and WHR all were correlated with lipid profile and blood pressure, while, in group II patients aged from 7079 years, BMI and WC, but not WHR were correlated with lipid profile and blood pressure. In group III aged 80 years and more, none of these indices were correlated with lipid profile or blood pressure.

In general, the prevalence of hypertension and high blood cholesterol increase with the increasing of BMI, as does the combined prevalence of both hypertension and dyslipidemia. ${ }^{(49)}$ Our results showed that the levels of total cholesterol, LDL-ch and triglycerides were significantly higher among hypertensive individuals. HDL-ch levels were significantly negatively correlated with hypertension in groups (II) and (III), but not in group (I).Other authors stated that HDL-ch is not considered as a marker for cardiovascular disease. ${ }^{(50,51)}$

In our study, hs-CRP was positively correlated with WC, WHR, hypertension, total cholesterol, triglycerides, LDL-ch, and negatively associated with HDL-ch, and positively correlated with BMI only in group III. In accordance with our results; Halcox JP, et $\mathrm{al}^{(52)}$ studied patients (aged $\geq 50$ years) from 12 European countries with at least one traditional cardiovascular risk factor but no history of cardiovascular disease, they found that CRP levels were positively correlated with BMI , and were negatively correlated with HDLchlevels. CRP levels were also higher in women. Among patients without diabetes mellitus who were not receiving statin therapy, approximately $30 \%$ had CRP levels $\geq 3 \mathrm{mg} / \mathrm{L}$, and approximately $50 \%$ had CRP levels $\geq 2 \mathrm{mg} / \mathrm{L}$, including those at intermediate levels of traditionally estimated cardiovascular risk.

Also, Seo SM, et $\mathrm{al}^{(53)}$ found that the levels of hsCRP were significantly increased from the low to the very high risk group $(0.15,0.23,0.27$ and 0.47 , respectively) and were significantly correlated with age, BMI, the levels of HDL-ch, 
LDL-ch/HDL-ch ratio, the LDL-ch/total cholesterol (TC) ratio, the HDL-ch/TC ratio, the HDL-C/triglyceride (TG) ratio and the TC/TG ratio. In a multivariate regression analysis, age, the HDL-C level, the LDL-C/TC ratio and BMI were found to be independently correlated with the hs-CRP level.

\section{Conclusion}

The prevalence of hypertension is a serious public health problem among elderly Egyptians. The prevalence of overweight/ obesity is also increasing in alarming proportions among the elderly. Overweight/obesity in terms of BMI and WC strongly correlated with the prevalence of hypertension, one of the major risk factors for cardiovascular diseases, and also strongly correlated with atherogenic dyslipidemia parameters. We observed a strong association of obesity indices and cardiovascular risk factors. CRP is more than a simple biomarker and current findings tightly link this protein with the atheromatous plaque. Assessing the hs-CRP levels may thus provide additive value in predicting cardiovascular risks. Primary prevention focusing on efforts to prevent the development of, and altering the hypertension risk factors have to be implemented. Secondary prevention should be carried out as well by focusing on slowing the progression of the disease after a diagnosis. Government should increase the public awareness on hypertension, obesity, and the advantages on healthy lifestyle. Screening CVD factors among older adults above 50 years old is an important preventive measure. More research, especially longitudinal research should be carried out on cardiovascular disease especially among institutionalized elderly since research on this field is lacking.

\section{References}

1. TJ Kizhakekuttu, ME Widlansky. Natural antioxidants and hypertension: promise and challenges. CardiovascTher 2010; 28 (4): pp. e20-e32.
2. Lewington, S; Clarke, R; Qizilbash, N; Peto, R; Collins, R; Prospective Studies, Collaboration. "Age-specific relevance of usual blood pressure to vascular mortality: a meta-analysis of individual data for one million adults in 61 prospective studies". Lancet 2002; 360 (9349): 1903-13.

3. Roger VL, Go AS, Lloyd-Jones DM, et al. Heart disease and stroke statistics--2012 update: a report from the American Heart Association. Circulation. 2012 Jan 3. 125(1):e2-e220.

4. The World Health Report 2002-Reducing Risks, Promoting Healthy Life. Geneva, Switzerland: World Health Organization; 2002.

5. Cornoni-Huntley J, LaCroix AZ, Havlik RJ. Race and sex differentials in the impact of hypertension in the United States. The National Health and Nutrition Examination Survey I Epidemiologic Follow-up Study. Arch Intern Med. 1989 Apr. 149(4):780-8.

6. Burt VL, Whelton P, Roccella EJ, Brown C, Cutler JA, Higgins M, et al. Prevalence of hypertension in the US adult population. Results from the Third National Health and Nutrition Examination Survey, 19881991. Hypertension. 1995 Mar. 25(3):30513.

7. Carretero OA, Oparil S; Oparil. "Essential hypertension. Part I: definition and etiology". Circulation 2000; 101 (3): 32935.

8. Rule AD, Fridley BL, Hunt SC, Asmann Y, Boerwinkle E, Pankow JS, et al. Genome-wide linkage analysis for uric acid in families enriched for hypertension. Nephrol Dial Transplant. 2009 Aug. 24(8):2414-20.

9. O'Brien, Eoin; Beevers, D. G.; Lip, Gregory Y. H. ABC of hypertension. London: BMJ Books.2007.

10. Grossman E, Messerli FH; Messerli. "Drug-induced Hypertension: An 
Unappreciated Cause of Secondary Hypertension". Am. J. Med 2012; 125 (1): 14-22.

11. Blood pressure Lowering Treatment Trialists' Collaboration. Effects of different regimens to lower blood pressure on major cardiovascular events in older and younger adults: meta-analysis of randomised trials. Br. Med. J 2008; 336, 1121-7.

12. Chobanian AV, Bakris GL, Black HR, Cushman WC, Green LA, Izzo JL Jr, et al. Seventh report of the Joint National Committee on Prevention, Detection, Evaluation, and Treatment of High Blood Pressure. Hypertension 2003; 42(6):120652.

13. Culleton BF, Larson MG, Kannel WB, Levy D. Serum uric acid and risk for cardiovascular disease and death: the Framingham Heart Study. Ann Intern Med 1999 Jul 6; 131(1):7-13.

14. Mortality after $10 \quad 1 / 2$ years for hypertensive participants in the Multiple Risk Factor Intervention Trial. Circulation 1990 Nov; 82(5):1616-28.

15. Rosini N, Machado MJ, Xavier HT. Study of the prevalence and multiplicity of cardiovascular risk factors in hypertensive individuals from the city of Brusque, SC, Brazil. Arq Bras Cardiol 2006; 86(3):21922.

16. Fabijanic D, Banic M, Kardum D. Creactive protein in cardiovascular risk evaluation. LijecVjesn 2006; 128(56):167-74.

17. Barbosa AR, Souza JMP, Lebrão ML, Laurenti R, Marucci MFN. Anthropometry of elderly residents in the city of São Paulo, Brazil. Cad SaúdePública. 2005; 21(6):1929-38.

18. Boyko EJ, Leonetti DL, Bergstrom RW, Newell-Morris L, Fujimoto WY. Visceral adiposity, fasting plasma insulin, and blood pressure in Japanese-Americans. Diabetes Care 1995; 18: 174-81.

19. Spiegelman D, Israel RG, Bouchard C, Willett WC. Absolute fat mass, percent body fat, and body-fat distribution: which is the real determinant of blood pressure and serum glucose? Am J ClinNutr 1992; 55: 1033-44.

20. Mueller WH, Wear ML, Hanis CL, Emerson JB, Barton SA, Hewett-Emmett $\mathrm{D}$, Schull WJ. Which measure of body fat distribution is best for epidemiologic research? Am J Epidemiol 1991; 133: 85869.

21. Pouliot MC, Despres JP, Lemieux S, Moorjani S, Bouchard C, Tremblay A, Nadeau A, Lupien PJ. Waist circumference and abdominal sagittal diameter: best simple anthropometric indices of abdominal visceral adipose tissue accumulation and related cardiovascular risk in men and women. Am J Cardiol 1994; 73: 460-8.

22. Ko FT, Chan JC, Woo J, Lau E, Yeung VT, Chow CC, Wai HP, Li JK, So WY, Cockram CS. Simple anthropometric indexes and cardiovascular risk factors in Chinese. Int $\mathbf{J}$ ObesRelatMetabDisord 1997; 21: 995-1001.

23. Pfützner A, Forst Th. High-Sensitivity C reactive protein as Cardiovascular Risk Marker in Patients with Diabetes Mellitus. Diabetes Technology \& Therapeutics 2006, 8(1): 28-36.

24. Ridker PM. C-reactive protein and the prediction of cardiovascular events among those at intermediate risk: moving an inflammatory hypothesis toward consensus. J Am CollCardiol 2007; 29;49(21):2129-38.

25. De Groot LC, Sette S, Zajkas G, Carbajal A, Amorim JA. Euronut SENECA investigators. Nutritional status: anthropometry. Eur J ClinNutr 1991; 45(45s3):31-42. 
26. World Health Organization. Obesity preventing and managing the Global Epidemic: Report of a WHO consultation on obesity. Geneva: World Health Organization, 1998.

27. National Cholesterol Education Program Expert Panel. Summary of the second report of the National Cholesterol Education Program Expert Panel on detection, evaluation and treatment of high blood cholesterol in adults. JAMA 1993; 269, 3015-23.

28. E. T. H. Yeh, J. T. Willerson, "Coming of age of C-reactive protein: using inflammation markers in cardiology," Circulation 2003; 107( 3):370-2.

29. The Expert Committee on the Diagnosis and Classification of Diabetes Mellitus. Follow-up report on the diagnosis of diabetes mellitus. Diabetes Care 2003; 26(11):3160-7.

30. MM Ibrahim. Problem of hypertension in Egypt. The Egyptian heart journal 2013; 65(3):233-4.

31. The Expert Committee on the Diagnosis and Classification of Diabetes Mellitus. Follow-up report on the diagnosis of diabetes mellitus. Diabetes Care 2003; 26(11):3160-7.

32. Ibrahim MM, Rizk H, Appel LJ, El Aroussy W, Helmy S, Sharaf Y, et al. Hypertension prevalence, awareness, treatment, and control in Egypt. Results from the Egyptian National Hypertension Project (NHP). NHP investigative team. Hypertension 1995; 26 (6): 886-90.

33. Amery A et al. Mortality and morbidity results from the European Working Party on High Blood Pressure In The Elderly Trial. Lancet 1985; 1:1349-54.

34. Huang KC, Lin WY, Lee LT, Chen CY, Lo $\mathrm{H}$, et al. Four anthropometric indices and cardiovascular risk factors in Taiwan. Int J ObesRelatMetabDisord 2002; 26: 1060-8.
35. Zhu S, Wang Z, Heshka S, Heo M, Faith MS, et al. Waist circumference and obesity-associated risk factors among whites in the third National Health and Nutrition Examination Survey: clinical action thresholds. Am J ClinNutr 2002; 76: 743-9.

36. Huang KC, Lee MS, Lee SD, Chang YH, Lin $\mathrm{YC}$, et al. Obesity in the elderly and its relationship with cardiovascular risk factors in Taiwan. Obes Res 2005; 13: 170-8.

37. Abolfotouh MA, Soliman LA, Mansour E,Farghaly M, et al.Central obesity among adults in Egypt: prevalence and associated morbidity.Eastern Mediterranean Health Journal; 2008, 14 (1).

38. Carr DB, Utzschneider KM, Hull RL et al. Intra-abdominal fat is a major determinantof the National Cholesterol Education Program Adult Treatment Panel III criteria forthe metabolic syndrome. Diabetes 2004; 53(8):2087-94.

39. Janghorbani M, Amini $M$, Walter $C$, et al.First Nationwide Survey of Prevalence of Overweight, Underweight, and Abdominal Obesity in Iranian Adults. Obesity 2007; 15(11): 2797-2808.

40. Steering Committee, International Association for the Study of Obesity. The Asia-Pacific perspective: redefining obesity and its treatment. Health Communications Australia, 2000.

41. Mueller WH, Wear ML, Hanis CL, Emerson JB, Barton SA, Hewett-Emmett $\mathrm{D}$, Schull WJ. Which measure of body fat distribution is best for epidemiologic research? Am J Epidemiol 1991; 133: 85869.

42. Bjorntorp P. The associations between obesity, adipose tissue distribution and disease. Acta Med Scand 1988; 723: (Suppl): 121-34.

43. Pouliot MC, Despres JP, Lemieux S, Moorjani S, Bouchard C, Tremblay A, 
Nadeau A, Lupien PJ. Waist circumference and abdominal sagittal diameter: best simple anthropometric indices of abdominal visceral adipose tissue accumulation and related cardiovascular risk in men and women. Am J Cardiol 1994; 73: 460-8.

44. Mykkanen L, Laakso M, Pyorala K. Association of obesity and distribution of obesity with glucose tolerance and cardiovascular risk factors in the elderly. Int J Obes Relat Metab Disord 1992; 16: 695-704.

45. Spiegelman D, Israel RG, Bouchard C, Willett WC. Absolute fat mass, percent body fat, and body-fat distribution: which is the real determinant of blood pressure and serum glucose? Am J ClinNutr 1992; 55: 1033-44.

46. Yusuf, S., S. Hawken and S. Ounpuu. Is waist to hip ratio a better marker of cardiovascular risk than body mass index? Lancet 2005; 366: 1640-9.

47. Zhu, S., S.B. Heymsfield, H. Toyoshima, Z. Wang, A.Pietrobelli and S. Heshka. Race-ethnicity-specific waist circumference cutoffs for identifying cardiovascular disease risk factors. Am. J. Clin. Nut 2005; 81: 409-15.

48. GavelerJS, Rosenblum E. Predictors of postmenopausal body mass index and waist hip ratio in the oklahoma postmenopausal health disparities study. J. Am. Coll. Nut 2003; 22: 269-76.

49. Brown CD, Higgins $M$, Donato KA, et al.Body mass index and the prevalence of hypertension and dyslipidemia. Obesty Res 2000; 8: 605-19.

50. Després, J.P., I. Lemieux, G.R. Dagenais, B. Cantin and B. Lamarche. HDLcholesterol as a marker of coronary heart disease risk: The québec cardiovascular study. Atherosclerosis 2000; 153: 263-72.
51. Assmann, G., H. Schulte, A. von Eckardstein and Y. Huang. High-density lipoprotein cholesterol as a predictor of coronary heart disease risk. The PROCAM experience and pathophysiological implications for reverse cholesterol transport. Atherosclerosis 1996; 124: S11S20.

52. Halcox JP, Roy C, Tubach F, BanegasJR,et al. C-reactive protein levels in patients at cardiovascular risk: EURIKA study.BMC CardiovascDisord. 2014 Feb $24 ; 14: 25$.

53. Seo SM, Baek SH, Jeon HK, Kang SM, et al.Correlations between the level of highsensitivity C-reactive protein and cardiovascular risk factors in Korean adults with cardiovascular disease or diabetes mellitus: the CALLISTO study.J AtherosclerThromb. 2013; 20(7):616-22. 